Vol. 5, No. 04; 2021

ISSN: $2581-3366$

\title{
Laparoscopic Reconstruction of a Type IIb Müllerian Anomaly: A Case Report
}

\author{
Elena Marín Ortiz ${ }^{1}$; Vanesa Rodríguez Fernández ${ }^{1}$; Irene García García ${ }^{1}$; Isabel Bernal Anido ${ }^{1}$; \\ Luis Heliodoro Alba Ordás ${ }^{\text {ss }}$. \\ ${ }^{1}$ Service of Obstetrics and Gynecology, Hospital Álvaro Cunqueiro, Vigo, Pontevedra, Spain \\ Elena Marín Ortiz \\ $+34650033899$ \\ Hospital Álvaro Cunqueiro. \\ Estrada Clara Campoamor 341, 36213. Vigo. Spain.
}

doi: 10.51505/ijmshr.2021.5402

URL: http://dx.doi.org/10.51505/ijmshr.2021.5402

\begin{abstract}
Uterine malformations consist of a group of miscellaneous congenital anomalies of the female genital system, being the unicornuate uterus the class most unfrequently diagnosed. It is related to an increase of obstetrics complications and in turn, the presence of a rudimentary horn is cause of chronic pelvic pain.

We report the case of a 29 yerar-old who came to our hospital with intense dysmenorrhea. Imaging techniques revealed a unicornuate uterus with a rudimentary horn. We performed a laparoscopic removal of this uterine anomaly without any complication in the postoperative period.

In our case report, we demonstrate the effectiveness of laparoscopy for the treatment of type IIb Müller abnormalities.
\end{abstract}

Keywords: Genital anomalies, Fertile age, Müllerian malformations, Pelvic pain

\section{INTRODUCTION}

Congenital uterine abnormalities are a heterogeneous group of uterine configurations that may adversely affect reproductive potential.

Unicornuate uterus represents $0.3-4 \%$ of the uterine anomalies, occurs in 1/5400 women and 74$90 \%$ are associated with a rudimentary horn. (1)

This anatomical abnormality may lead to many obstetrical and gynaecologic complications. Besides gynaecologic complications such as endometriosis, chronic pelvic pain, hematometra and primary infertility, there may be obstetrical problems as well, such as ectopic pregnancy, early abortion and premature birth. (2)

\section{CASE REPORT}

The patient is a 29-year-old, nulligravid, woman who arrives at Gynaecology and Obstetrics service of the Álvaro Cunqueiro Hospital due to severe dysmenorrhea. 
International Journal of Medical Science and Health Research

Vol. 5, No. 04; 2021

ISSN: $2581-3366$

Previously she was treated with oral combined hormonal contraceptives and with a subdermal contraceptive implant without clinical improvement.

The ultrasound scan shows two hemiuterus separated by a thick septum (10-12 mm). (Figure 1) The next therapeutic step was to administer Decapeptyl and perform a magnetic resonance imaging (MRI).

MRI reports a left unicornuate uterus with a rudimentary right horn that has its own endometrial cavity and does not communicate with the left hemiuterus. (Figure 2)

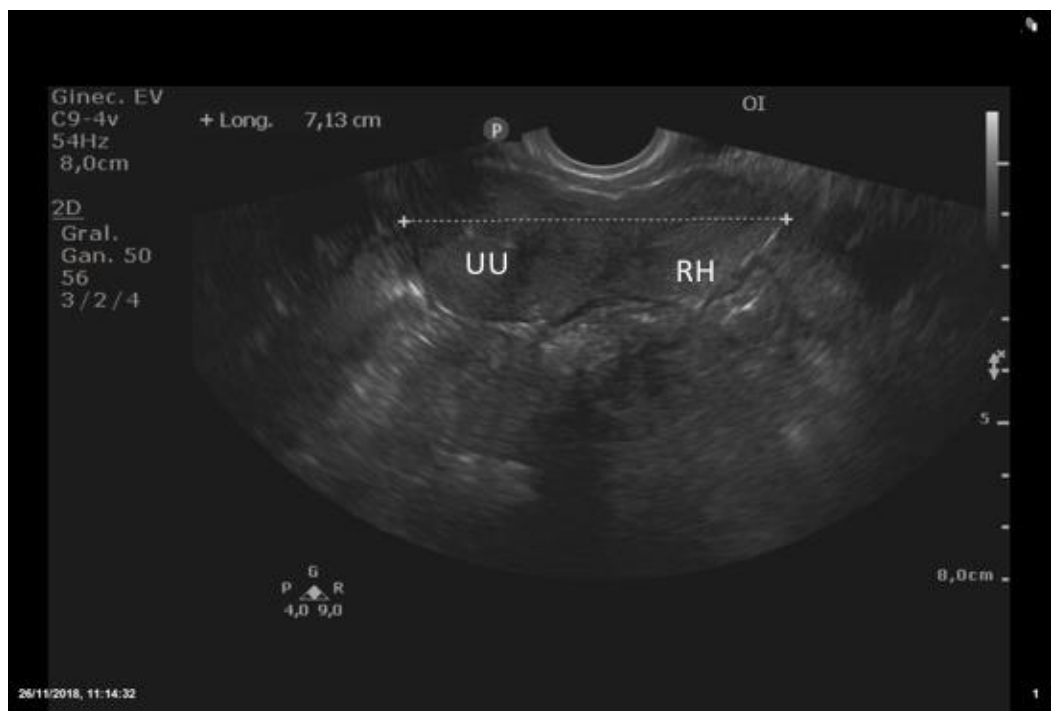

Figure 1 . The $2 \mathrm{D}$ vaginal ultrasound scan shows the unicornuate uterus (UU) and the rudimentary horn $(\mathrm{RH})$.

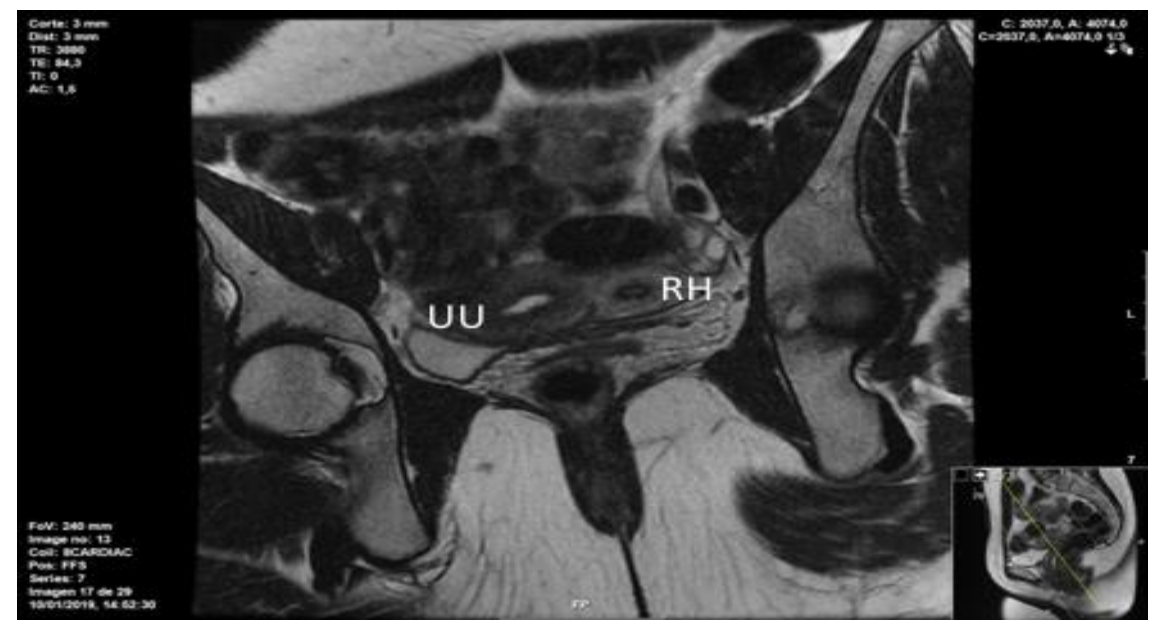

Figure 2. Magnetic resonance imaging showing the unicornuate uterus (UU) and the rudimentary horn $(\mathrm{RH})$. 


\section{International Journal of Medical Science and Health Research}

Vol. 5, No. 04; 2021

ISSN: $2581-3366$

Due to the refractory synthoms it was decided to perform resection of the right horn by laparoscopy.

Exploratory findings during laparoscopy were a unicornuate uterus with a non-communicating and larger right horn. Both ovaries and Fallopian Tubes were normal in shape and size. Right Fallopian Tube communicated with right hemiuterus. Right uterine artery supplied the left hemiuterus. (Figure 3a)

Other findings were endometriotic lesions in the anterior pelvic peritoneum and the pouch of Douglas.

The surgical technique was a resection of the right hemiuterus and right salpingectomy with bipolar cautery and harmonic energy.

Then, there was performed a selective coagulation of the hemi hysterectomy bed in the left hemiuterus junction area. The piece was removed by endoscopic morcellation by a $12 \mathrm{~mm}$ suprapubic trocar insertion site.

The integrity of the left hemiuterus cavity and permeability of the left Fallopian Tube were checked by the administration of blue methylene liquid. The total surgical time was 100 minutes.

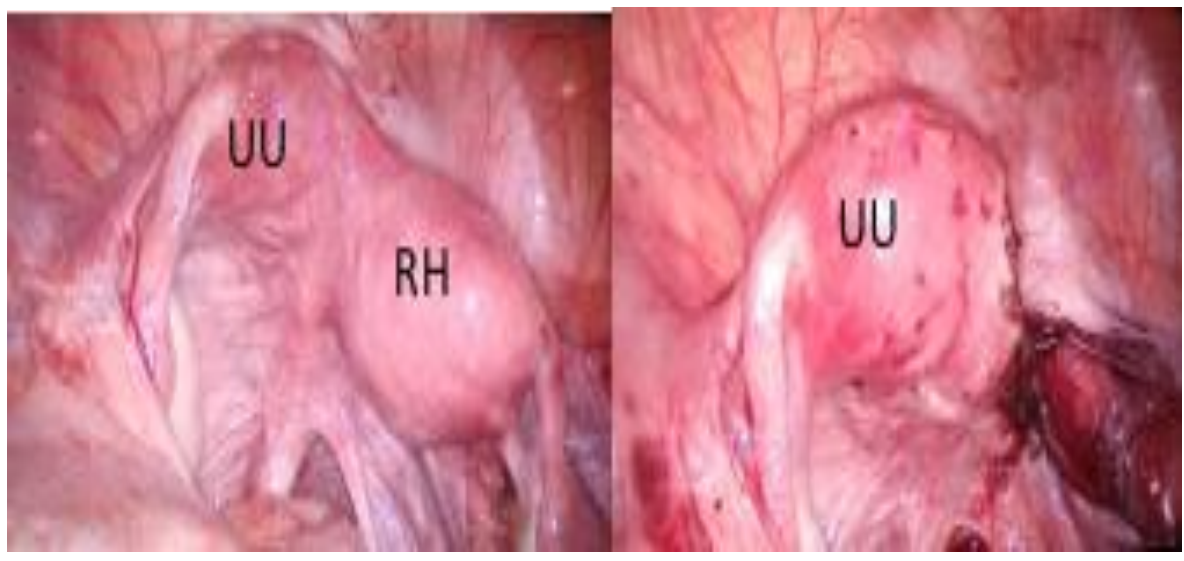

(a)

(b)

Figure 3. Anatomy before (a) and after (b) removal of the rudimentary horn. Unicornuate uterus (UU), rudimentary horn $(\mathrm{RH})$

Pathological examination of the specimen confirmed the diagnosis. Our patient evolved without complications in the postoperative period.

The patient experimented clinical improvement in subsequent controls, without recurrence in her pelvic pain.

\section{DISCUSSION}

A unicornuate uterus with a non-communicating rudimentary horn belongs to group II-b of the classification of the American Society of Reproductive Medicine (ASRM). This subtype of anomaly has a very low incidence when compares with other gynaecological pathologies, estimated approximately 1 per 100.000 women of fertile age. (3) 


\section{International Journal of Medical Science and Health Research}

Vol. 5, No. 04; 2021

ISSN: 2581-3366

This subtype of anomaly is associated with endometriosis, by means of a retrograde menstruation, and also with renal abnormalities, both of which should be assessed before any treatment. These patients usually present with diffuse pelvic pain and dysmenorrhea caused by hematometra in the rudimentary horn, endometriosis, pyometra or torsion of the abnormal portion of the Fallopian Tube.

Patients with a non-communicating rudimentary uterine horn present with cycle-dependent or cycle-independent pelvic pain.

These patients also have a higher rate of ectopic pregnancies and miscarriage, as well as preterm deliveries when they succeed in getting pregnant. (4)

It is important that appropriate treatment be given not only to symptomatic patients but also to asymptomatic women with a uterine horn containing endometrium, in order to avoid retrograde menses, endometriosis, and adhesions. The gold standard for the treatment of a rudimentary uterine horn is excision by the use of laparoscopy or laparotomy. The rapid advancement of minimally invasive surgery in recent years permits laparoscopic or hysteroscopic treatment in most cases. However, in view of the small case numbers treated so far, the procedure should be confined to specialized laparoscopic centers. (5)

The surgical technique of choice has to be adapted to the type of malformation. There are some details in the surgery that need to be keep in mind. First, in our case there was a well-defined limit between the unicornuate uterus and the rudimentary horn what made the surgery easier. Hysteroscopy could be useful in such a case, since opening the uterine cavity may affect future reproduction. In our case we administrated blue methylene liquid to check the integrity of the uterine cavity. Secondly, we removed the Fallopian Tube on the side of the rudimentary horn in order to avoid tubal pregnancies.

\section{CONCLUSION}

A left unicornuate uterus with a rudimentary right horn is an unusual disease with symptoms that worsen the quality of life and with a medical treatment which is not effective in most cases.

Our report demonstrates that operative laparoscopy can be used for a successful and minimally invasive removal of a rudimentary horn.

\section{CONFLICTS OF INTEREST}

I declare to be free of any personal or comercial association that may mean a conflict of interest, as well as we have respected the ethical principles of researh.

We attached the ICMJE form for Disclosure of Potencial Conflicts of Interest.

\section{INFORMED CONSENT}

The patient gave the verbal consent to publish her clinical case with medical purpose. 


\section{International Journal of Medical Science and Health Research}

Vol. 5, No. 04; 2021

ISSN: 2581-3366

\section{REFERENCES:}

- G.S. Letterie. Management of congenital uterine abnormalities. Reprod Biomed Online, 23 (1) (2011) pp. 40-52, 10.1016/j.rbmo.2011.02.008

- Grimbizis GF, Camus M, Tarlatzis BC, Bontis JN, Devroey P. Clinical implications of uterine malformations and hysteroscopic treatment results. Hum Reprod Update 2001; 7:161-174

- Acien P. Incidence of Mülleran defects in fertile and infertile woman. Hum Reprod 1997; 12:1372-1376.

- Atmaca R, Germen AT, Burak F, Kafkasli A. Acute abdomen in a case with noncommunicating rudimentary horn and unicornuate uterus. JSLS. 2005; 9(2): 235-237.

- Gitas G, Eckhoff K, Rody A, Ertan AK, Baum S, Hoffmans E, Alkatout I. An unprecedented occult non-communicating rudimentary uterine horn treated with laparoscopic excision and preservation of both fallopian tubes: a case report and review of the literature. $\mathrm{J}$ Med Case Rep. 2021 Feb 4;15(1):51. doi: 10.1186/s13256-020-02636-x. PMID: 33536066; PMCID: PMC7860579

- Zapardiel I, Alvarez P, Perez-Medina T, Bajo-Arenas JM. Laparoscopic management of a cavitated non-communicating rudimentary uterine horn of a uni-cornuate uterus: a case report. J Med Case Reports 2010; 4:215.

Avaliable from: https://doi.org/10.1186/1752-1947-4-215

- Ruggeri G, Gargano T, Antonellini C, Carlini V, Randi B, Destro F, Lima M. Vaginal malformations: a proposed classification based on embryological, anatomical and clinical criteria and their surgical management (an analysis of 167 cases). Pediatr Surg Int. 2012 Aug;28(8):797-803. doi: 10.1007/s00383-012-3121-7. PMID: 22806600.

- Hořejší J. Congenital developmental defects of derivates of müllerian ducts. Endocr Dev. 2012;22:251-270. doi: 10.1159/000331689. Epub 2012 Jul 25. PMID: 22846534.

- Kıykaç Altınbaş Ş, Tapısız ÖL, Ünsal M, Moraloğlu Tekin Ö. Laparoscopic hemihysterectomy in a noncommunicating uterine horn: The critical steps to be considered. Turk J Obstet Gynecol. 2020 Jun;17(2):143-145. doi: 10.4274/tjod.galenos.2020.01709. Epub 2020 Jul 29. PMID: 32850191; PMCID: PMC7406904.

- Faller E, Baldauf JJ, Becmeur F, Lehn A, Akladios CY, Lecointre L. Laparoscopic Management of a Rudimentary Uterine Horn. J Minim Invasive Gynecol. 2018 Jul-Aug; 25 (5):769-770. doi: 10.1016/j.jmig.2017.10.027. Epub 2017 Nov 11. PMID: 29133151.

- Whynott RM, Mejia RB. Laparoscopic resection of functional, noncommunicating uterine horn in close approximation to functional hemiuterus. Fertil Steril. 2020 Aug; 114 (2):436-437. doi: 10.1016/j.fertnstert.2020.05.013. Epub 2020 Jul 9. PMID: 32654816.

- Mabrouk M, Arena A, Zanello M, Raimondo D, Seracchioli R. Unicornuate uterus with noncommunicating functional horn: diagnostic workup and laparoscopic horn amputation. Fertil Steril. 2020 Apr; $113 \quad$ (4):885-887. doi: 10.1016/j.fertnstert.2019.12.003. PMID: 32228882.

- Liatsikos SA, Tsikouras P, Souftas V, Ammari A, Prassopoulos P, Maroulis G, Liberis V. Diagnosis and laparoscopic management of a rudimentary uterine horn in a teenage girl, presenting with haematometra and severe endometriosis: our experience and review of 
Vol. 5, No. 04; 2021

ISSN: 2581-3366

literature. Minim Invasive Ther Allied Technol. 2010 Aug; 19 (4):241-7. doi: 10.3109/13645701003644491. PMID: 20367539.

- Raźnikiewicz A, Korlacki W, Grabowski A. The role of laparoscopy in paediatric and adolescent gynaecology. Wideochir Inne Tech Maloinwazyjne. 2020 Sep; 15 (3):424436. doi: 10.5114/wiitm.2020.97817. Epub 2020 Aug 3. PMID: 32904632; PMCID: PMC7457195.

- Jan H, Katesmark M, Ghai V. A Stepwise Approach to Laparoscopic Excision of a Noncommunicating Rudimentary Horn. J Minim Invasive Gynecol. 2019 MayJun;26(4):600-601. doi: 10.1016/j.jmig.2018.07.009. Epub 2018 Jul 19. PMID: 30031204 . 